\section{Source and concept evaluation as determinants of inferred assertions*}

\author{
ABRAHAM TESSER and DAVID HAIGLER \\ University of Georgia, Athens, Ga. 30601
}

Within the context of congruity theory, the following hypotheses were tested: (1) When both source and concept (where concept is another person) are evaluated with a similar sign, a positive assertion will be assumed; otherwise, a negative assertion will be assumed. (2) What source is assumed to assert about concept should not differ from what concept is assumed to assert about source. Sixty-four Ss were given a list of historical figures and asked to choose what they thought each would say about some of the others from a list of assertions that ranged from definitely positive to definitely negative. The results supported Hypothesis 1 . While Hypothesis 2 was not supported, there was a systematic effect, whereby the less positively evaluated figure in each pair was inferred to be more charitable in his assertions than vice versa.

Congruity theory (Osgood \& Tannenbaum, 1957) is concerned with predicting attitute change in communication situations. It predicts that when a source makes an assertion (either positive or negative) about a concept there will be pressures on the recipient of the message to change his attitude toward the source and/or the concept, unless his attitude toward both the source and the concept are equally polarized (i.e., extreme) and of like signs in the case of positive assertions or different signs in the case of negative assertions. Further, the theory predicts that attitudes will move toward equal polarity, with the relatively less polarized attitude changing more than the more polarized attitude. In addition to attitude toward source, attitude toward concept, and direction of assertion, Osgood and Tannenbaum have included an empirical assertion constant that takes account of the fact that, all things being equal, attitudes toward the concept change more than attitudes toward the source. Finally, when the linkage between the source and the concept is too incongruous, a correction for incredulity might be necessary. While the exact numerical predictions of the theory have not always been correct, the theory does seem to do a good job in rank ordering the magnitude of change (Zajonc, 1968).

The three major components of the theory are attitude toward source, attitude toward concept, and direction of assertion. Both attilude toward source and attitude towair concept are treated differently from the assertion.

One difference (although not a necessary one) between source/concept and assertion is their

*The authors wish to thank Sidney Rosen for his valuable comments on an earlier draft of this paper. typical status as theoretical variables. Congruity theory has concerned itself with attitude change or change in evaluation of the source/concept and thus, has always considered the assertion to be an independent variable. It is possible to argue, howeer, that the assertion, in addition to helping determine source/concept attitude change when it is fixed, will vary as a function of source/concept attitudes. when they are fixed, and it (the assertion) is free to vary. The purpose of this study is to explore this possibility.

The following hypotheses guided the research. Assuming that Ss have the opportunity of picking what they think source will say about concept from a number of assertions ranging from definitely positive to definitely negative, then: (1) if both source and concept are positively evaluated by Ss or both source and concept are negatively evaluated by $\mathrm{Ss}$, the assertion picked will be positive; if source is evaluated positively and concept is evaluated negatively, or vice versa, the assertion picked will be negative; (2) if both the source and the concept are persons, then the assertion chosen for Person $A$ as source and Person $B$ as concept should not differ from the assertion chosen for Person B as source and Person $A$ as concept (i.e., symmetry should obtain).

In order to test these hypotheses, Ss were asked to evaluate a number of historical world figures. They were also asked to indicate, by picking one of several assertions ranging from definitely positive to definitely negative, what they thought each figure would say about some of the other figures.

\section{METHOD}

The Ss $(\mathrm{N}=66)$ were male $(\mathrm{N}=22)$ and female $(\mathrm{N}=44)$ students enrolled in applied and social psychology courses at the University of Georgia in the early fall of 1968 .
Six American and world figures from each of three historical periods were selected such that, in the authors' opinion, all of the figures would be known to the Ss and three within each period would be negatively evaluated and three would be positively evaluated. The three periods were the American Revolution, including Benedict Arnold, King George III (King of England during the revolution ${ }^{1}$ ), General Cornwallis (British general in American Revolution), Thomas Jefferson, Benjamin Franklin, and George Washington; the Second World War, including Adolf Hitler, Benito Mussolini, Joseph Stalin, Harry Truman, Franklin D. Roosevelt, and Winston Churchill; post World War II, including Fidel Castro, Ho Chi Minh, Alexi Kosygin, Dwight D. Eisenhower, John F. Kennedy, and John Glenn.

An evaluation booklet was prepared, containing the names in a randomized order. Each name was paired with a series of seven 7-point semantic differential scales. Four of the seven scales were evaluative (good-bad, likeable-dislikeable, p l e a s a $\mathrm{t}$ - u n p l e a s a $\mathrm{n}$, valuable-worthless) and were designed to tap the Ss' attitude toward each of the figures.

An assertions booklet was also prepared. This booklet contained 18 items, one for each of the figures. Each item contained a name imbedded in the sentence: "Indicate what you think [NAME] is most likely to have said about the following people." Beneath this sentence the names of the five other figures in that particular historical period were listed along with space to indicate which assertion would be made about each. The assertions were selected from the following set of alternatives, which were printed on an instruction sheet accompanying each booklet. "After having given the matter considerable thought: A. I am quite positive that 's contribution to

history has been beneficial to mankind. B. I am not positive, but I think that _. 's contribution to history has been beneficial to mankind. C. I don't know whe $t h$ er contribution to history has been beneficial or harmful to mankind. D. I am not positive, but I think that 's contribution to history has been harmful to mankind. E. I am quite positive that 's contribution to history has been harmful to mankind."

The order of the 18 names was randomized independently for the assertion booklet, and the order of five other names for the period was 
Table 1

Historical Figures: How They are Evaluated and What They Assert About Each Other

\begin{tabular}{|c|c|c|c|c|c|c|c|c|}
\hline \multirow{2}{*}{$\frac{\text { Revolutionar }}{\mathbf{A}^{*}}$} & \multirow{2}{*}{$\frac{\text { War Figures }}{\mathrm{B}}$} & \multirow{2}{*}{$\begin{array}{c}\text { Mean } \\
\text { Assertion } \neq \\
\end{array}$} & \multicolumn{2}{|c|}{ World War II Figures } & \multirow{2}{*}{$\begin{array}{c}\text { Mean } \\
\text { Assertiont }\end{array}$} & \multicolumn{2}{|c|}{ Post World War II Figures } & \multirow{2}{*}{$\begin{array}{c}\text { Mean } \\
\text { Assertiont }\end{array}$} \\
\hline & & & $\mathbf{A}^{*}$ & B & & $\mathbf{A}^{*}$ & B & \\
\hline $\begin{array}{l}\text { Arnold } \\
M=-6.03 \\
S=5.33\end{array}$ & $\begin{array}{l}\text { Jefferson } \\
\text { Washington } \\
\text { Franklin } \\
\text { George III } \\
\text { Cornwallis }\end{array}$ & $\begin{array}{r}-.95 \\
-1.07 \\
-.75 \\
.70 \\
.60\end{array}$ & $\begin{array}{l}\text { Hitler } \\
M=-8.95 \\
S=\quad 3.12\end{array}$ & $\begin{array}{l}\text { Truman } \\
\text { Rooseveit } \\
\text { Churchill } \\
\text { Mussolini } \\
\text { Stalin }\end{array}$ & $\begin{array}{r}-1.68 \\
-1.77 \\
-1.65 \\
1.21 \\
.25\end{array}$ & $\begin{array}{l}\text { Castro } \\
M=-7.97 \\
S=\mathbf{3 . 8 8}\end{array}$ & $\begin{array}{l}\text { Eisenhower } \\
\text { Kennedy } \\
\text { Glenn } \\
\text { Ho-Chi-Minh } \\
\text { Kosygin }\end{array}$ & $\begin{array}{r}-1.48 \\
-1.53 \\
-1.01 \\
.94 \\
1.16\end{array}$ \\
\hline $\begin{array}{r}\text { George III } \\
M=-2.59 \\
S=4.80\end{array}$ & $\begin{array}{l}\text { Jefferson } \\
\text { Washington } \\
\text { Franklin } \\
\text { Cornwallis }\end{array}$ & $\begin{array}{l}-.77 \\
-.75 \\
-.36 \\
1.46\end{array}$ & $\begin{array}{l}\text { Mussolini } \\
\mathrm{M}=-7.09 \\
\mathrm{~S}=\mathbf{3 . 2 3}\end{array}$ & $\begin{array}{l}\text { Truman } \\
\text { Roosevelt } \\
\text { Churchill } \\
\text { Stalin }\end{array}$ & $\begin{array}{r}-1.43 \\
-1.38 \\
-1.30 \\
.49\end{array}$ & $\begin{array}{l}\text { Ho-Chi-Minh } \\
M=-\mathbf{5 . 7 5} \\
\mathrm{S}=\mathbf{4 . 8 2}\end{array}$ & $\begin{array}{l}\text { Eisenhower } \\
\text { Kennedy } \\
\text { Glenn } \\
\text { Kosygin }\end{array}$ & $\begin{array}{r}-1.41 \\
-1.32 \\
-.97 \\
.51\end{array}$ \\
\hline $\begin{array}{rr}\text { Cornwallis } \\
M= \\
S=\quad 4.26\end{array}$ & $\begin{array}{l}\text { Jefferson } \\
\text { Washington } \\
\text { Franklin }\end{array}$ & $\begin{array}{l}-.46 \\
-.43 \\
-.06\end{array}$ & $\begin{array}{l}\text { Stalin } \\
M=-5.05 \\
S=\quad 4.84\end{array}$ & $\begin{array}{l}\text { Truman } \\
\text { Roosevelt } \\
\text { Churchill }\end{array}$ & $\begin{array}{r}-1.13 \\
-.97 \\
-.84\end{array}$ & $\begin{array}{l}\text { Kosygin } \\
M=-1.29 \\
S=4.30\end{array}$ & $\begin{array}{l}\text { Eisenhower } \\
\text { Kennedy } \\
\text { Glenn }\end{array}$ & $\begin{array}{l}-.80 \\
-.53 \\
-.47\end{array}$ \\
\hline $\begin{array}{l}\text { Jefferson } \\
M=9.88 \\
S=2.94\end{array}$ & $\begin{array}{l}\text { Washington } \\
\text { Franklin }\end{array}$ & $\begin{array}{l}1.71 \\
1.74\end{array}$ & $\begin{array}{l}\text { Truman } \\
\mathrm{M}=\mathbf{6 . 9 7} \\
\mathrm{S}=\mathbf{3 . 9 8}\end{array}$ & $\begin{array}{l}\text { Roosevelt } \\
\text { Churchill }\end{array}$ & $\begin{array}{l}1.34 \\
1.42\end{array}$ & $\begin{array}{c}\text { Eisenhower } \\
\mathrm{M}=\mathbf{9 . 0 3} \\
\mathrm{S}=\mathbf{3 . 4 8}\end{array}$ & $\begin{array}{l}\text { Kennedy } \\
\text { Glenn }\end{array}$ & $\begin{array}{l}1.44 \\
1.53\end{array}$ \\
\hline $\begin{array}{l}\text { Washington } \\
M=10.38 \\
S=2.12\end{array}$ & Franklin & 1.79 & $\begin{array}{l}\text { Roosevelt } \\
\mathrm{M}=\mathbf{9 . 0 5} \\
\mathrm{S}=\mathbf{3 . 6 0}\end{array}$ & Churchill & 1.69 & $\begin{array}{l}\text { Kennedy } \\
M=10.24 \\
S=2.57\end{array}$ & Glenn & 1.82 \\
\hline $\begin{array}{l}\text { Franklin } \\
M=10.82 \\
S=2.05\end{array}$ & & & $\begin{array}{l}\text { Churchill } \\
M=9.79 \\
S=2.79\end{array}$ & & & $\begin{array}{l}\text { Glenn } \\
M=10.42 \\
S=2.09\end{array}$ & & \\
\hline
\end{tabular}

*The evaluative mean (M) and standard deviation (S) are presented below each name for that name.

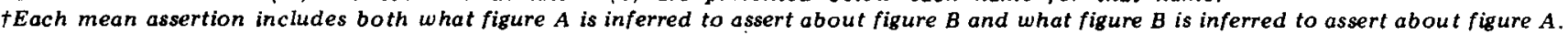

randomized independently for each name.

Both booklets were filled out by Ss during class time. Only one booklet was filled out per session, and the two sessions were 2 days apart. Approximately half the Ss filled out the evaluations booklet first, and the others filled out the assertions booklet first.

\section{RESULTS AND DISCUSSION}

In order to test the hypotheses, it is first necessary to obtain the evaluation of each of the figures. This was done by summing across the four 7-point evaluation scales for each figure. Since each scale was scored from -3 to +3 , the most negative score was -12.00 and the most positive score, +12.00 . Examination of the means reveals that all those figures who were assumed to be positively evaluated are positively evaluated and all those figures who were assumed to be negatively evaluated are negatively evaluated except for General Cornwallis whose mean evaluation (.45) is slightly positive (see Table 1). This mean, however, does not differ significantly from zero $(t<1)$.

Given the evaluations of the figures, it is possible to test Hypothesis 1 ; namely, if the source and concept are of like sign, the assertion picked will be positive, and, if the source and assertion are of different sign, the assertion picked will be negative. It will be recalled that $S s$ were given a choice between five assertions which ranged from definitely positive to definitely negative for each source/concept combination. The Ss' choices were scored from -2.00 , for definitely negative, to +2.00 , for definitely positive. Hypothesis 1 can be evaluated by examining the mean assertion over what Figure $A$ said about Figure $B$ and what Figure $B$ said about Figure A. Examination of these means for the World War II and post World War II figures reveals that the hypothesis is upheld in all cases (see Table 1). That is, like-sign pairs produce positive assertions; unlike-sign pairs produce negative assertions. Cornwallis presents a problem for the Revolutionary War figures. $\mathrm{He}$ is not evaluated differently from zero, his mean evaluation is slightly positive, and yet he functions as if he is negatively evaluated in the assertions produced for the pairs in which he is a member. All the pairs, not including Cornwallis, do produce the predicted assertions, however. But for Cornwallis, it appears that Hypothesis 1 is supported by the data. As Zajonc (1960) has pointed out, congruity theory can be mapped into balance theory, and researchers working within this framework have shown that $S$ s tend to fill in relations consistent with this hypothesis.

Hypothesis 2 states that the assertion that $A$ makes about $B$ should be the same as the assertion $B$ makes about $A$.

An analysis of the difference in what each member of each pair asserts about the other member does not support the hypothesis. It appears that the less positively (or more negatively) evaluated member of the pair is more positive in what he is perceived to assert about the other than vice versa. The data bearing on this point may be summarized as follows: of the 45 pairs, 40 of the assertion differences in the direction mentioned above have been obtained. Twenty-six of these 40 are significantly different from zero $(p<.05)$. Of the five assertion differences not in this direction, four are in the opposite direction, and only one of these significantly so $(p<.01)$. Looking across all pairs, 40 vs 5 is significantly different from a split that would be expected if both directions were equally probable $\left(x^{2}=27.22\right.$; $\left.\mathrm{p}<.01^{2}\right)$.

In order to follow up on this unexpected finding, a further post hoc hypothesis was tested. This hypothesis may be stated as follows: The greater the evaluative difference between members of a pair, the greater the algebraic differences in what they assert about each other. It will be noted that this hypothesis is not stated in terms of like-sign or unlike-sign pairs as was Hypothesis 1 . The reason for this is that there is no apparent shift in sign for the two pair types. The hypothesis was tested by correlating the rank order of the algebraic difference in assertion with the rank order of the difference in evaluation. The resulting correlation was .41 $(\mathrm{p}<.01$; see Note 2$)$. This correlation seems to be coming primarily from the revolutionary figures $(p=.67)$ rather than from the 
World War II $(p=.17)$ or the post World War II $(\mathrm{p}=.33)$ figures.

One possible explanation for the lack of symmetry in assertions is that, when the $S$ evalutes a public figure, he does so on the basis of attributes that are available to anyone evaluating that figure, including the figure's contemporaries. Since figures that are positively evaluated have positive attributes and figures that are negatively evaluated have negative attributes, "reality" demands that the assertions made about positive figures be positive and assertions made about negative figures be negative. If one combines the "reality" demands with the necessity for congruity, the obtained results are explicable. Congruity forces and "reality" both lead to a negative assertion in the case of a positive source and a negative concept. In the case of a negative source with a positive concept congruity demands a negative assertion, while "reality" demands a positive assertion. Since "reality" cannot be completely denied even by a negatively evaluated figure, the result in this case, is a less negative assertion. In general, to the extent that the source is more positive than the concept, both "reality" and congruity tend to increase the negativity or decrease the positivity of the assertion. To the extent that the source is less positive than the concept, congruity works in the direction of negativity, while "reality" works in the direction of positivity; hence, the obtained asymmetry with positive sources less charitable than less positive sources.

This finding would seem to bear on the question of incredulity. What the data suggest is that it would be more believable for a positive source to reject a negative source than vice versa. In fact, while the present finding of asymmetry was unanticipated, Leaf, Kanouse, Jones, \& Abelson (1968) have, in the context of analyzing the believability of sentences, reported similar findings. Looking at balance effects of subject-verb-object sentences, they found that: "Predicate balance represented the largest observed balance effect [p. 424]." That is, all things being equal, sentences in which "good" people were the object of positive verbs and sentences in which "bad" people were the object of negative verbs were more believable than vice versa.

On the whole, this study demonstrates that the assumed assertion one person will make about another is systematically responsive to the evaluative sign of both figures in the pair and the direction of the assertion (i.e., A about B vs B about A). Further, it would suggest that congruity theory should be extended

to take into account: (1) changes in the perceied assertion as a dependent variable that might operate in addition to or as an alternative to attitude change on the source/concept and (2) determinants of incredulity beyond degree of incongruity as presently defined.

\title{
REFERENCES
}

LEAF, W. A., KANOUSE, D. E., JONES, J. J., \& ABELSON, R.P. Balance, character expression, and the justice principle: An analysis of sentence evaluations. Proceedings of th 76 th Annual Convention of the American Psychological Association, 1968 , 423-424.

OSGOOD, C. E., \& TANNENBAUM, P. H. The principle of congruity in the prediction of attitude change. Psychological Review, 1955, 62, 42-55.

\section{Perceptual recognition and guessing behavior by normal and educable retarded children*}

\author{
LARRY M. RASKIN. LOUELLA J. FONG, and KATHRYN N. BLACK \\ Purdue University, Lafayette, Ind. 47907
}

This study was concerned with the recognition of fragmented (or incomplete) stimulus forms by normal and educable-retarded children (EMRs) at two MA levels. A series of 12 slides was presented, and the number of brief exposure periods required to make a correct identification was recorded. The analyses of the results showed that younger MA Ss need more exposures to identify these forms. While there were no effects of IQ, the EMRs made many more incorrect guesses than did the normals, and the younger EMRs guessed more than all other children.

The present study was concerned with the recognition of tachistoscopically presented fragmented line drawings by two MA levels of normal and educable-retarded children (EMRs). The number of 10-msec exposures required for correct identification of each picture, as well as incorrect responses, was recorded. The use of the brief exposure technique was based on the finding of Haber and his coworkers (e.g., Haber, 1965; Haber \& Hershenson, 1965; Haber \& Hillman, 1966 ; Hershenson \& Haber, 1965) that the probability of correct identification increases with repeated presentations. Thus, it provides a measure of the amount of experience necessary to establish a percept, a process which may be influenced both by level of intellectual functioning (normal or EMR) and intellectual development (MA). In conjunction with the above, the response styles of the two IQ populations were examined.

* The authors wish to thank the Tippecanoe School Corporation for their cooperation in this research project. Authors Raskin and Black are at the Department of Child Development and Family Life, Purdue University, Lafayette, Indiana 47907. Professor Fong is now at Western Kentucky State University. Reprints are available from the first author. Parts of this paper were presented at the Eastern Psychological Association meeting, Atlantic City, New Jersey, April 1970.

\section{SUBJECTS}

Forty-six educable mentally retarded children (EMRs) and 46 normals, 23 kindergartners and 23 third graders, served as Ss. IQ and MA scores for all children were obtained with the Peabody Picture Vocabulary Test, Form B. EMRs were divided into older and younger groups at the median MA of 7-0. Mean MA, CA, and IQ for the older group of EMRs were $8-8,14-0$, and 70.7 , while the younger EMRs had mean MA, CA, and IQ scores of $5-8,9-6$, and 68.3 , respectively. The older normals (third graders) had mean MA, CA, and IQ of 8-11, 9-0, and 98.2, while those of the kindergartners were $5-11,6-0$, and 98.1.

\section{MATERIALS}

A pretraining series of forms was developed. Five fragmented white ink drawings (leaf, ship, arm and fist, flag and flagpole, key) were shown on $3 \times 5$ in. pieces of black construction paper. A test series composed of 12 slides was also created. Each slide contained a single fragmented white drawing on a black background. (Figure 1 shows these in a reversed black-white relationship for ease in looking at on the printed page.) The slides were shown with a Kodak Carousel slide projector equipped with a tachistoscopic shutter. 